\title{
Obstructive sleep apnoea: patients' experiences of oral appliance treatment
}

\author{
E. NORDIN*, M. STENBERG ${ }^{\dagger}$ \& A. TEGELBERG* ${ }^{\dagger}{ }^{\ddagger}{ }^{*}$ Faculty of Odontology, Malmö university, \\ Malmö, ${ }^{\dagger}$ Centre of Clinical Research, Uppsala university, Västerås, and ${ }^{\star}$ Postgraduate Dental Education Center, Public Dental Service, \\ Örebro, Sweden
}

SUMMARY Over the past few decades, there has been a pronounced increase in the number of patients being treated by general dental practitioners for obstructive sleep apnoea (OSA). The purpose of this study was to survey the care and patient experiences and the self-reported effectiveness of OSA treatment with an oral appliance (OA) incorporating mandibular advancement. The design was a retrospective, cross-sectional study, with follow-up between 6 months to 1 year after commencement of treatment. A survey form was posted to 1150 subjects, identified in the regional register over a 1year period as having been treated with an $\mathrm{OA}$ for OSA. The questionnaire comprised 70 questions and assertions in various domains, such as general health/lifestyle, changes in symptoms/quality of life and sleep-related experiences, daytime sleepiness, changes in life situation, evaluation of treatment and the value of treatment. The overall response rate was
$64 \%(n=738)$. Treatment with OA gave relief of symptoms in $83 \%$ of the respondents. Quality of life, somatic and cognitive symptoms improved significantly in patients who used the appliance frequently $(P<\mathbf{0 . 0 0 1})$. Daytime sleepiness decreased significantly $(P<0.001)$. Treatment satisfaction and willingness to recommend the similar treatment to a friend were high ( $>85 \%)$. OA treatment of OSA by general dental practitioners is a safe procedure. Most of the survey respondents experienced relief of symptoms. Those who used their appliance frequently reported improvement in quality of life, somatic and cognitive symptoms. Excessive daytime sleepiness was reduced in the majority of the patients under treatment.

KEYWORDS: dentistry, effectiveness, follow-up, PROM, questionnaire, treatment

Accepted for publication 8 January 2016

\section{Introduction}

Obstructive sleep apnoea (OSA) is a public health issue. When daytime sleepiness is included, the condition affects $2 \%$ of women and $4 \%$ of men (1). OSA is characterized by disordered breathing and intermittent hypoxaemia (2). There are correlations with hypertension, cardiovascular disease, stroke and premature death (3-6). Patients with OSA report diminished quality of life (QoL), cognitive dysfunction and impaired general health because of respiratory disorders $(3,7-11)$.

The goal of treatment is to reduce the negative daytime symptoms and improve respiration. The aim of all treatment modalities was to widen the respiratory space, either by removing the excess tissues or by stimulating the airway opening.

The three most common treatments for the condition are as follows: continuous positive airway pressure (CPAP) (12), surgical removal of the soft tissue in the throat and intra-oral appliances combined with mandibular advancement (OA). Treatment with $\mathrm{OA}$ is undertaken by dentists: the appliance holds the mandible in a protruded position. Studies have shown that OA successfully reduces respiratory disturbances in $57-81 \%$ of mild and moderate OSA, and in $14-61 \%$ of more severe cases $(13,14)$. For more severe conditions, CPAP is the preferred therapy option 
(3). However, compliance with CPAP is reported to vary between 51 and $76 \%$, depending on the followup time $(3,15)$, indicating a need for alternative therapy options. Improved QoL is reported for the three most widely used treatment modalities (16-18) and improvement in neurocognitive skills $(12,19)$.

Over the past few decades, the number of patients being treated with OA by their general dental practitioners has increased and has become much more frequent in Sweden than in the other Nordic countries (3). Questions have been raised about patient compliance and the quality of treatment, and not least about patients' experiences of this long-term treatment. These issues are seldom addressed in the literature.

The purpose of this study was to evaluate the care and patients' reported experiences of OA treatment of OSA performed in general dental practice.

\section{Materials and methods}

\section{Materials}

The study was based in southern Sweden, in the region of Scania, with a population of about 1200 000. During a l-year period, from 2009 to 2010, the regional register showed that 1150 patients had undergone OA treatment for a medically verified diagnosis of OSA: the treatment had been provided by 66 dentists in the Public Dental Service and 77 private practitioners.

\section{Method}

The design was a retrospective cross-sectional study, with follow-up approximately $>6$ months to 1 year after commencement of treatment. The follow-up comprised a survey in the form of a questionnaire, posted to all patients identified in the regional register. The participants received written information about the purpose of the study and were advised that participation was voluntary and could be withdrawn by not responding to the survey. The participants were requested to return the completed questionnaire within 2 weeks. Those who did not respond to the first mailing were sent a reminder. The participants' identities were protected in the survey through the use of a serial number only.

The survey covered a total of 70 questions in 12 key areas, covering frequency and degree of discom- fort/change (in Likert scales, 3 to 7 grades). These key areas were as follows: personal data, general health, lifestyle, treatment experiences, treatment effects, treatment compliance, drowsiness/sleepiness, satisfaction, health treatment, assessment of treatment importance/value and quality of life. The questionnaire also included the Epworth Sleepiness Scale (ESS), which is a validated index for detecting excessive daytime sleepiness $(20,21)$. Most of the questions have been used in a previous study (22).

In open fields of the survey, the respondents had the option of describing experiences not adequately covered by the survey questions. The questionnaire was pre-tested for content and language comprehension in a group of 10 volunteers, 5 of non-dental background and 5 in the dental profession. The questionnaire was revised to take into account the comments received from the volunteers.

The study design was tested and approved by the local ethics committee at the Faculty of Odontology, Malmö University, Sweden.

\section{Statistics}

The descriptive analysis included the mean, standard deviation and percentage distribution. Intergroup differences at baseline and during treatment with respect to the perceived factors and somatic and cognitive symptoms were tested with the McNemar test. Spearman's correlation (two-tailed) test was used to investigate any significant differences between satisfaction with treatment with respect to the quality of life and with respect to the frequency of appliance use. In all tests, a $P$-value $<0.05$ was regarded as statistically significant. The data were analysed using IBM SPSS Statistics, version $20 *$.

\section{Results}

The overall response rate was 64\%: $70 \%$ in males and $30 \%$ in females. The mean age was 58 years: 57 $( \pm 32)$ in males and $61( \pm 37)$ in females. Self-reported general medical and pain conditions are shown in Table 1. At follow-up, $85 \%$ of the respondents had been under treatment for $>1$ year and the remaining $15 \%$ for $>6$ months. In $55 \%$ of cases, the respondents

*SPSS Inc., Chicago, IL, USA. 
Table 1. Self-reported general medical and pain conditions $(n=738)$

\begin{tabular}{ll}
\hline Body mass index $\left(\mathrm{kg} / \mathrm{m}^{2}\right)$ & \\
Male & $27 \cdot 8 \pm 3 \cdot 5$ \\
Female & $27 \cdot 6 \pm 4 \cdot 9$ \\
Obese $(\mathrm{BMI}>30), \%$ & 23 \\
Male & 28 \\
Female & 64 \\
Self-report of systemic disease, \% & 10 \\
Diabetes & 15 \\
Cardiovascular disease & 36 \\
Hypertension & 5 \\
Prostatic complaints & 19 \\
Frequent headache after treatment & \\
(>once a week), \% & 68 \\
No sleep disturbance due to pain, \% & \\
\hline
\end{tabular}

were treated in private general practice, $43 \%$ were treated by dentists in the Public Dental Service and $2 \%$ were treated at the Dental School in Malmö.

The experienced waiting time for professional care by dentists and physicians varied somewhat throughout the region: $19-25 \%$ experienced the wait as long or very long, while $34-45 \%$ felt that the time was short or very short.

The type of OA used was a monobloc design in $90 \%(n=568)$, moving the mandible into protrusion. In $10 \%(n=63)$, bibloc OA was used, comprising two parts which can be moved towards each other, but also with the mandible in a protruded position. In $92 \%(n=532)$, the OA was made of hard acrylic and in $8 \%(n=48)$ of a soft elastomer material.

Regular use of the appliance, every night for the past month, was reported by $61 \%$ of respondents: $73 \%$ used it $\geq 5$ nights/week, while $17 \%$ had not used their $\mathrm{OA}$ at all. Of those using their OA, $71 \%$ wore it throughout sleep, and $11 \%$ wore it for $75 \%$ of sleeping time. The remains wore it less than the above mentioned.

Excessive daytime sleepiness (ESS), measured as $>11$ points, was reported by $23 \%$ of the respondents, with a mean value of 7.5. Before treatment, only $26 \%$ felt refreshed after a night's sleep: there was a significant increase in frequency after treatment, $77 \%$ $(P<0.001)$.

Compared with those who did not drink any type of fluid $1 \mathrm{~h}$ before bedtime, no association was disclosed, either before or during treatment with $\mathrm{OA}$, between beverage intake $1 \mathrm{~h}$ before bedtime and the need to urinate nocturnally. The majority of the
Table 2. Respondents' experience of using the oral appliance during the past month and the level of treatment satisfaction

\begin{tabular}{lcr}
\hline Q: How satisfied are you with the use of the oral appliance? $(n=672)$ \\
Answer & $n$ & $\%$ \\
Very well & 274 & 41 \\
Well & 209 & 31 \\
Neither well nor bad & 84 & 13 \\
Bad & 39 & 6 \\
Very bad & 66 & 10 \\
Q: How satisfied are you with the received treatment? $(n=646)$ & \\
Answer & 212 & 31 \\
Very satisfied & 286 & 42 \\
Satisfied & 119 & 17 \\
Neither satisfied nor dissatisfied & 29 & 4 \\
Dissatisfied & 40 & 6 \\
Very dissatisfied & & \\
\hline
\end{tabular}

respondents felt that the ease of use of their OA had been 'very good' or 'good'. A greater proportion of patients were 'very satisfied' or 'satisfied' with the treatment, (Table 2). Of the patients who were satisfied with the treatment (very satisfied or satisfied), $81 \%$ had favourable experiences of medical care and $83 \%$ of dental care. The level of satisfaction with the prescribed type of OA was 'very satisfied' or 'satisfied' for the monobloc type in $76 \%$, for the bibloc type in $66 \%$ and with the OA of hard acrylic in $74 \%$ and of soft elastomer in $68 \%$, respectively.

Men and women were equally satisfied with the treatment. The respondents presented for follow-up at their dentists in $44 \%(n=322)$ of cases and at their physicians in $25 \%(n=184)$ of cases. Of those who had undergone follow-up at the dentists, $78 \%$ were very satisfied or satisfied with the treatment and $8 \%$ were completely dissatisfied or dissatisfied. Of those who attended follow-up by their physician, $80 \%$ were 'very satisfied' or 'satisfied' and $8 \%$ were 'completely dissatisfied' or 'dissatisfied'. Of the respondents who had not attended a follow-up appointment with the dentist, $68 \%$ were 'very satisfied' or 'satisfied', while $10 \%$ were 'completely dissatisfied' or 'dissatisfied'. The corresponding levels of satisfaction among those who did not attend a follow-up appointment with their physician were as follows: $73 \%$ 'very satisfied' or 'satisfied' and $14 \%$ 'completely dissatisfied' or 'dissatisfied'.

There was a correlation between the frequency of use (number of nights/week during the past month) and improved quality of life at follow-up $(r=0.34$, 
$P<0.01)$ and treatment satisfaction $(r=0.58$, $P<0.01)$.

After the start of treatment, $30 \%$ of respondents had undergone an objective assessment of the current respiratory status and a follow-up sleep recording, with the OA inserted. Of those who had undergone sleep recording, $46 \%$ had not been informed of the outcome.

In a self-assessment of their general QoL during treatment, $77 \%$ of the women and $72 \%$ of the men reported positive improvement (very much/very/ quite good). Deterioration was reported by $2 \%$ of the women and $1 \%$ of the men, while $21 \%$ of the women and $26 \%$ of the men reported no change.

Self-recorded experiences before and during treatment are shown in Table 3. Table 4 presents the respondents' somatic and cognitive symptoms before treatment and at follow-up, showing statistically significant differences $(P<0.001)$.

Table 5 shows the respondents' self-reported assessment of their physical strength, mental energy, concentration ability, well-being/joyfulness, social intercourse and general QoL before treatment and at follow-up. For the different domains, there was a positive change (very much better/much better) in 22 to $39 \%$. General QoL was rated as greatly improved by $39 \%$ of the respondents. In $<1 \%$, a sharp deterioration in the different domains was reported.

Table 3. Self-reported experiences of daytime and night-time complaints before treatment and at follow-up (\%)

\begin{tabular}{llll}
\hline Self-reported experiences & $\begin{array}{l}\text { Before } \\
\text { treatment }\end{array}$ & $\begin{array}{l}\text { At } \\
\text { follow-up }\end{array}$ & $\begin{array}{l}\text { Difference, } \\
P \text {-value }\end{array}$ \\
\hline $\begin{array}{c}\text { Refreshed after a night's } \\
\text { sleep (very often, often) }\end{array}$ & 27 & 83 & $<0.001$ \\
$\begin{array}{c}\text { Daytime tiredness (very } \\
\text { tired, tired) }\end{array}$ & 70 & 26 & $<0.001$ \\
$\begin{array}{l}\text { Mean number of } \\
\text { disturbances ( } \geq 2 \text { times } \\
\text { during sleep) }\end{array}$ & 65 & 41 & $<0 \cdot 001$ \\
$\begin{array}{l}\text { Waking up with need to } \\
\text { urinate ( } \geq 1 \text { time/night) }\end{array}$ & 70 & 67 & Ns \\
$\begin{array}{c}\text { Complaint about noisy } \\
\text { snoring sounds often, } \\
\text { sometimes) }\end{array}$ & 88 & 48 & $<0 \cdot 001$ \\
$\begin{array}{l}\text { Use of hypnotics for sleep } \\
\text { (often, sometimes) }\end{array}$ & 13 & 12 & Ns \\
\hline
\end{tabular}

Mc Nemar test.
Table 4. Self-reported somatic and cognitive symptoms, daytime and night-time, before treatment and at follow-up (\%)

\begin{tabular}{llll}
\hline Self-reported experiences & $\begin{array}{l}\text { Before } \\
\text { treatment }\end{array}$ & $\begin{array}{l}\text { At } \\
\text { follow-up }\end{array}$ & $\begin{array}{l}\text { Difference, } \\
P \text {-value }\end{array}$ \\
\hline $\begin{array}{l}\text { During sleep (often) } \\
\quad \text { Dry mouth }\end{array}$ & 48 & 31 & $<0 \cdot 001$ \\
$\quad$ Wake up and need & 36 & 21 & $<0 \cdot 001$ \\
$\quad$ to urinate & & & \\
$\quad$ Sweating & 29 & 14 & $<0 \cdot 001$ \\
$\quad$ Respiratory arrests & 77 & 12 & $<0 \cdot 001$ \\
$\quad$ Snoring sounds & 93 & 22 & $<0 \cdot 001$ \\
Daytime (often) & & & \\
$\quad \begin{array}{l}\text { Daytime sleepiness } \\
\text { Reduced concentration }\end{array}$ & 66 & 21 & $<0 \cdot 001$ \\
$\quad$ Increased mental & 28 & 11 & $<0 \cdot 001$ \\
$\quad$ irritability & & 9 & $<0 \cdot 001$ \\
Decreased libido & 26 & 16 & $<0 \cdot 001$ \\
$\quad \begin{array}{l}\text { Anguish, anxiety and } \\
\text { panic symptoms }\end{array}$ & 19 & 8 & $<0 \cdot 001$ \\
\hline
\end{tabular}

Mc Nemar test.

Of those who used the OA regularly, 85\% of respondents would recommend this type of treatment to a friend with the same problem ('Yes, absolutely').

\section{Discussion}

This study evaluated patients' reported experiences and outcomes after an intervention treating the verified OSA with an OA. Self-assessment data before and after at least 6 months of treatment showed that the patients perceived positive changes in QoL, somatic and cognitive symptoms. Satisfaction with the treatment was high. Furthermore, the patients reported that the OA was easy to use and functioned well.

With respect to the prevalence of general medical conditions among the study subjects, the results are consistent with those of other studies (23). Obesity has a negative effect on the progression of OSA and is thereby a negative prognostic factor. The prevalence of obesity was lower in this study than in other OSA studies, but higher than in the general population of Sweden (12\%) (23).

No significant difference was reported in the need to urinate at night before or during treatment, even though a remarkably high percentage of the respondents reported drinking within an hour of bedtime. These habits were the same as before treatment, and this explains why nocturnal urinary need/frequency was unchanged. 
Table 5. Self-reported life situation at follow-up, compared with before treatment start (\%)

\begin{tabular}{|c|c|c|c|c|c|c|}
\hline & $\begin{array}{l}\text { Physical } \\
\text { strength }\end{array}$ & $\begin{array}{l}\text { Mental } \\
\text { energy }\end{array}$ & $\begin{array}{l}\text { Concentration } \\
\text { ability }\end{array}$ & $\begin{array}{l}\text { Social } \\
\text { intercourse }\end{array}$ & $\begin{array}{l}\text { Well-being/ } \\
\text { joyfulness }\end{array}$ & $\begin{array}{l}\text { General quality } \\
\text { of life }\end{array}$ \\
\hline Very much better & 3 & 4 & 3 & 4 & 5 & 6 \\
\hline Much better & 21 & 23 & 19 & 20 & 20 & 33 \\
\hline Somewhat better & 39 & 33 & 34 & 32 & 30 & 35 \\
\hline No difference & 34 & 38 & 40 & 42 & 42 & 28 \\
\hline Somewhat worse & 17 & 3 & 3 & 2 & 3 & 1 \\
\hline Much worse & 1 & $0 \cdot 2$ & 0.5 & 0.5 & $0 \cdot 5$ & $0 \cdot 2$ \\
\hline Very much worse & 1 & $0 \cdot 2$ & $0 \cdot 2$ & $0 \cdot 2$ & $0 \cdot 2$ & $0 \cdot 2$ \\
\hline
\end{tabular}

Frequent headache in association with OSA is described in several studies and reported to affect between 35 and $50 \%$ of patients (24). In the present study, no data were available on the pre-treatment frequency of headache. One-tenth of the respondents reported frequent headaches, and $>50 \%$ had almost never experienced headache during actual treatment. It is probable that the frequency of headache decreased during treatment, as described in an earlier study by Tegelberg et al. (25).

It was equally common for patients to be treated in public dental clinics as in private practice, suggesting that this form of therapy is now accessible not only by referral to specialist clinics, but is widely available through general dental practitioners in this part of Sweden.

The monobloc appliance was the most frequent treatment modality at that time. It is the most reliable type of intra-oral device, the most thoroughly investigated and the earliest to be scientifically verified (13). Recently, several studies comparing monobloc and bibloc appliances have disclosed only minor differences in efficacy; hence, more treatment options are available for patients (14). Differences in the cost of production of the different types of appliance and own skills as dentist may be a factor contributing to the frequent use of the monobloc OA in Sweden. In later clinical studies, the results of bibloc appliances seem to have some superior effect due to better compliance compared to a monobloc design $(26,27)$. Whether or not adjustable oral appliances improve the effectiveness better than monobloc appliances remains uncertain, and rigorous prospective randomized clinical trials evaluation are required. The use of either a monobloc or bibloc appliance could not be analysed by the op-outs in the study, and thereby, we could not answer the question whether the bibloc appliances have any superior effect.
OA with mandibular advancement reduces nocturnal respiratory arrest/disturbances more efficiently than appliances which do not include advancement. This is more evident in severe OSA (28). Mandibular advancement in the structure of the $\mathrm{OA}$ is therefore considered to be critical for treatment effectiveness (14). The most common choice of material for OA was position and the occlusion. In most studies, the most common range of follow-up times is from 1 to 5 years, with few extending over longer periods (29). In one long-term follow-up study, the orthodontic side effects were more pronounced with appliances made of hard acrylic than soft elastomeric appliances (30). Patient satisfaction was comparable for the different types of $\mathrm{OA}$ and was not influenced by the choice of material or construction. The level of satisfaction may also be associated with the good therapeutic effect (14).

The proportion of patients who experience occlusal changes increases during the first 2 years of treatment and then remains relatively constant. Previous reports have shown that the dental/occlusal changes are usually minor and at times imperceptible to the patient $(28,30)$. The prerequisites for treatment to proceed are the absence of unacceptable or progressive symptoms and the presence of adequate posterior support (30). In the absence of knowledge about factors contributing to these occlusal changes, it may be important to continue follow-up even if it does not increase satisfaction with the treatment.

The study showed that those who used their OA very frequently perceived a greater improvement in their QoL after treatment than those who used their OA less frequently. This finding has not been presented in the previous studies. The OA only exerts an effect when in active use (14); hence, those patients who used their OA more frequently may have per- 
ceived a greater benefit from the treatment. However, it is most likely that the patient's perception of wellbeing and quality of life improved because treatment relieved the symptoms (16).

Regular use of OA, that is 5 nights or more per week, was reported by $73 \%$, which is in agreement with the other studies $(25,31,32)$. When treatment compliance is inadequate, it is important to evaluate the OA therapy and to interact with the patient's physician to find the alternative treatment to relieve symptoms and improve the patient's quality of life.

All signs and symptoms asked about in the survey had declined significantly in comparison with the pretreatment values, especially for episodes of apnoea, snoring and daytime sleepiness. Similar results are reported in other studies with reference to daytime sleepiness, irritability, sweating and the need to urinate at night (33). The treatment effect was that $77 \%$ of respondents had an ESS value $<11$, which is considered to be non-morbid daytime sleepiness, and average value was 7.5 during treatment, which is similar to another study $(19,34)$.

We found no differences between those who attended follow-up at their dentist and/or physician and those who did not. Satisfaction with the treatment was the same. Studies of CPAP have shown that appointments to monitor treatment improve patient compliance (33). Similar effects might be achieved for all patients if those showing poor compliance with the OA treatment were encouraged by more frequent recall to continue treatment. It was a smaller proportion of patients who had been on the subsequent verification of their treatment were satisfied with the treatment compared to the percentage of all study materials that were satisfied with the treatment. This might be because they had treatment problems sought care for the post.

A small number of patients underwent follow-up sleep recording as a part of the medical evaluation of the condition. Almost $50 \%$ of the respondents did not know whether they had undergone follow-up sleep recording. From the perspective of quality of medical care, it is then difficult to draw conclusions about the respiratory effect of the treatment. Respiratory disturbances increase the risk of, for example, cardiovascular disease: hence, medical practitioners have a responsibility to treat obstructive sleep apnoea effectively.

For the majority of patients, both dental and medical care had been a good experience. When OSA is treated as a multifactorial condition with several personal care contacts, one can imagine that the patient feels noticed and is therefore more likely to be satisfied with the treatment.

There was a wide range of waiting times in the study. There are no other studies related to waiting times in health care in the treatment of OSA, but the variation may be due either to personal traits such as impatience and disease activity or to pronounced regional variations in waiting times.

The majority of the respondents rated their quality of life as higher at follow-up, which is consistent with other studies. Treatment with OA, surgery or CPAP can all provide an increase in perceived QoL of patients $(21-25,28)$. Physical strength, mental energy, ability to concentrate and to feel joyfulness as well as social intercourse increased or remained unchanged in almost all patients during treatment, which is in accordance with other studies (33).

Most of the respondents were willing to recommend OA therapy to a friend, regardless of whether they had themselves perceived a positive treatment result or not.

The limitation of this kind of study is the ability to generalize from the results of a questionnaire depends on a sufficient number of responders. In this study, there was an overall response rate of $64 \%$. A response rate of at least $60 \%$ is set as a minimum requirement for publication by some scientific journals (35). However, there is a steady decline in response rates in the published surveys of healthcare providers in the USA, and during 2005-2008, only about 35\% met the $60 \%$ criteria and none in 2009 (36). This was also true for postal surveys of healthcare professionals covering 1996 to 2005 where the response rate $(350$ studies, average response rate 58\%) was significantly lower than the previous 10-year period. It was even lower in studies with more than 1000 participants. The conclusion drawn in 2005 was that response rates to postal surveys of healthcare professionals were low and probably declining, which may lead to the unknown levels of bias (37). With this as background, we find the results as reliable as possible at that time and with this research design. However, the results should be interpreted with some caution as the nonresponders could be more frequent non-satisfied patients to the treatment.

It can be concluded that OA treatment of OSA by a general dental practitioner is safe and gives symp- 
tomatic relief in the majority of patients. Quality of life, somatic and cognitive symptoms changed favourably for the patients who used their appliances frequently. The majority reported that treatment reduced excessive daytime sleepiness.

\section{Acknowledgments}

Financial support was given from Region Skåne and the Faculty of Odontology, Malmö University, Sweden.

\section{Ethical approval}

The study design was tested and approved by the local ethics committee at the Faculty of Odontology, Malmö University, Sweden.

\section{Declaration of interest}

The authors report no conflict of interests. The authors alone are responsible for the content and writing of the paper.

\section{References}

1. Young T, Palta M, Dempsey J, Skatrud J, Weber S, Badr S. The occurrence of sleep-disordered breathing among middle-aged adults. N Engl J Med. 1993;328:1230-1235.

2. Bassiri AG, Guilleminault C. Clinical features and evaluation of obstructive sleep apnoea-hypopnoea syndrome. Philadelphia: W.B. Saunders Co; 2000:869-878.

3. Franklin K, Rehnqvist N, Axelsson S. Obstructive Sleep Apnoea Syndrome, A Systematic Literature Review. Stockholm: Statens beredning för medicinsk utvärdering (SBU); 2007. SBU-rapport nr 184E. ISBN 978-91-85413-16-4.

4. Bixler EO, Vgontas AN, Lin H-M, Have TT, Rein J, VelaBueno A et al. Prevalence of sleep-disordered breathing in women. Am J Respir Crit Care Med. 2001;163:608-613.

5. Peppard PE, Young T, Palta M, Skatrud J. Prospective study of the association between sleep-disordered breathing and hypertension. N Engl J Med. 2000;342:1378-1384.

6. Lavie P, Herer P, Hoffstein V. Obstructive sleep apnoea syndrome as a risk factor for hypertension: population study. BMJ. 2000;320:479-482.

7. Baldwin CM, Griffith KA, Nieto FJ, O'Connor GT, Walseben JA, Redline S. The association of sleep disordered breathing and sleep symptoms with quality of life in the Sleep Heart Health Study. Sleep. 2001;24:96-105.

8. Engleman HM, Douglas NJ. Sleep. 4: sleepiness, cognitive function, and quality of life in obstructive sleep apnoea/hypopnoea syndrome. Thorax. 2004;59:618-622.

9. Yaffe K, Laffan AM, Harrison SL, Redline S, Sprira AP, Ensrud KE et al. Sleep-disordered breathing, hypoxia, and risk of mild cognitive impairment and dementia in older women. JAMA. 2011;306:613-619.

10. Beebe DW, Gozal D. Obstructive sleep apnoea and the prefrontal cortex: towards a comprehensive model linking nocturnal upper airway obstruction to daytime cognitive and behavioural deficits. J Sleep Res. 2002;11:1-16.

11. Naëgelé B, Thouvard V, Pépin JL, Lévy P, Bonnet C, Perret JE et al. Deficits of cognitive executive functions in patients with sleep apnoea syndrome. Sleep. 1995;18:43-52.

12. White J, Cates C, Wright J. Continuous positive airways pressure for obstructive sleep apnoea. Cochrane Database Syst Rev. 2002;2:CD001106.

13. Lim J, Lasserson TJ, Fleetham J, Wright J. Oral appliances for obstructive sleep apnoea. Cochrane Database Syst Rev. 2006;2006(1):CD004435.

14. Ahrens A, McGrath C, Hägg U. A systematic review of the efficacy of oral appliance design in the management of obstructive sleep apnoea. Eur J Orthod. 2011;33:318-324.

15. Sawyer AM, Gooneratne NS, Marcus CL, Ofer D, Richards KC, Weaver TE. A systematic review of CPAP adherence across age groups: clinical and empiric insights for developing CPAP adherence interventions. Sleep Med Rev. 2011;15:343-356.

16. Walker-Engström M-L, Wilhelmsson B, Tegelberg $\AA$, Dimenäs E, Ringqvist I. Quality of life assessment in treatment of obstructive sleep apnoea with a dental appliance and uvulopalatopharyngoplasty. J Sleep Res. 2000;9:303-308.

17. Naismith SL, Winter VR, Hickie IB, Cistulli PA. Effect of oral appliance therapy on neurobehavioral functioning in obstructive sleep apnoea: a randomized controlled trial. J Clin Sleep Med. 2005;1:374-380.

18. Lojander J, Kajaste S, Maasilta P, Partinen M. Cognitive function and treatment of obstructive sleep apnea syndrome. J Sleep Res. 1999;8:71-76.

19. Tegelberg $\AA$, Wilhelmsson B, Erixon-Lindroth N, Lindström L. Improved cognitive function after treatment with an oral appliance in obstructive sleep apnea. Nat Sci Sleep. 2012;4:89-96.

20. Johns MW. A new method for measuring daytime sleepiness: the Epworth sleepiness scale. Sleep. 1991;14:540-545.

21. Johns MW. Reliability and factor analysis of the Epworth Sleepiness Scale. Sleep. 1992;15:376-381.

22. Tegelberg $\AA$, Nohlert E, Bergman L-E, Andrén A. Bed partners' and patients' experiences after treatment of obstructive sleep apnoea with an oral appliance. Swed Dent J. 2012;36:35-43.

23. Lurie A. Metabolic disorders associated with obstructive sleep apnoea in adults. Adv Cardiol. 2011;46:67-138.

24. Alberti A, Mazzotta G, Gallinella E, Sarchielli P. Headache characteristics in obstructive sleep apnoea syndrome and insomnia. Acta Neurol Scand. 2005;111:309-316.

25. Tegelberg A, Wilhelmsson B, Walker-Engström ML, Ringqvist $M$, Andersson L, Krekmanov L et al. Effects and adverse events of a dental appliance for treatment of obstructive sleep apnoea. Swed Dent J. 1999;23:117-126.

26. Lettieri CJ, Paolino N, Eliasson AH, Shah AA, Holley AB. Comparison of adjustable and fixed oral appliances for the treatment of obstructive sleep apnea. J Clin Sleep Med. $2011 ; 7: 439-445$. 
27. Dieltjens M, Vanderveken OM, Van den Bosch D, Wouters $\mathrm{K}$, Denollet J, Verbraecken JA et al. Impact of type D personality on adherence to oral appliance therapy for sleepdisordered breathing. Sleep Breath. 2013;17:985-991.

28. Walker-Engström M-L, Ringqvist I, Westling O, Wilhelmsson B, Tegelberg A. A prospective randomized study comparing two different degrees of mandibular advancement with a dental appliance in treatment of severe obstructive sleep apnoea. Sleep Breath. 2003;7:119-130.

29. Wiman Eriksson E, Leissner L, Isacsson G, Fransson A. A prospective 10-year follow-up polygraphic study of patients treated with a mandibular protruding device. Sleep Breath. 2015;19:393-401.

30. Marklund M. Predictors of long-term orthodontic side effects from mandibular advancement devices in patients with snoring and obstructive sleep apnoea. Am J Orthod Dentofacial Orthop. 2006;129:214-221.

31. Fransson AMC, Tegelberg $\AA$, Leissner L, Wenneberg B, Isacsson G. Effects of a mandibular protruding device on the sleep of patients with obstructive sleep apnea and snoring problems: a 2-year follow-up. Sleep Breath. 2003;7:131141.

32. Tegelberg $\AA$, Walker-Engström M-L, Vestling O, Wilhelmsson B. Two different degrees of mandibular advancement with a dental appliance in treatment of patients with mild to moderate obstructive sleep apnoea. Acta Odontol Scand. 2003;61:356-362.

33. Holmdahl C, Schöllin I-L, Alton M, Nilsson K. CPAP treatment in obstructive sleep apnoea: a randomised, controlled trial of follow-up with a focus on patient satisfaction. Sleep Med. 2009; 10:869-874.

34. Wilhelmsson B, Tegelberg $\AA$, Walker-Engström M-L, Ringqvist $\mathrm{M}$, Andersson L, Krekmanov L et al. A prospective randomized study of a dental appliance compared with uvulopalatopharyngoplasty in the treatment of obstructive sleep apnoea. Acta Otolaryngol (Stockh). 1999;1 19:503-509.

35. Journal of the American Medical Association: JAMA instructions for authors. Available at: http://jama.jamanetwork.com/public/instructionsForAuthors.aspx\#GeneralInformation, accessed 13 October 2015.

36. McLeod CC, Klabunde CN, Willis GB, Stark D. Health care provider surveys in the United States, 2000-2010: a review. Eval Health Prof. 2013;36:106-126.

37. Cook JV, Dickinson HO, Eccles MP. Response rates in postal surveys of healthcare professionals between 1996 and 2005: an observational study. BMC Health Serv Res. 2009;9:160.

Correspondence: Åke Tegelberg, Postgraduate Dental Education Center, Public Dental Service, PO Box 1126, SE-701 11 Örebro, Sweden. E-mail: ake.tegelberg@regionorebrolan.se 